\title{
Collaborations, Scale Invariance, and The Extended Trust
}

\author{
Robert Duncan, Vice Chancellor for Research, University of Missouri
}

$\mathrm{B}$ e cautious in your trust of this, or any other document concerning collaborations that is created under single authorship! It should, at first glance, seem as suspect as yet another monotonic lecture on the virtues of interactive teaching.

But there is actually an imbedded message here: We don't collaborate for collaboration sake, but rather we collaborate out of our mutual desire to improve our individual performance, and hence our individual condition, beyond the level that we can obtain through our efforts in isolation. This is the first and most fundamental criteria for a successful collaboration. If it is missing, then the individual's participation in the collaboration will not be sustainable. Secondly, we look for the collaboration to provide an immediate market for our efforts. We see ourselves, and more importantly others see us, as bringing some rare skill or perspective to the larger effort that is valued, and that value will help increase the significance of the entire effort. This second condition must be met as well for a genuine collaboration to be sustained. Remarkably this is 'scale-invariant', since it applies to collaborations where each individual is a person, group of people, corporation, and even nations.

\section{Three Classes of Collaborations}

Let me define three basic classes of collaborations: The first class of collaborations is the most common, and hence the class that I used in the lead-in to this essay above. It consists of collaborations between individuals (again, people, corporations, or nations) that depend on each other to accomplish a more complex objective than they could achieve on their own. The second general class of collaborations exists between different disciplines or different schools of thought, generally in an effort to define new approaches to our common problems that defy solution through a single disciplined approach.
While certainly individuals will be the vehicles of these disciplines and thoughts, it none-the-less is useful to think more abstractly of these collaborations in a class by themselves, since in this class the point of view or professional approach becomes the generalized 'individual' in this higherorder concept of collaboration. Finally, a third class of collaborations has recently been defined through our ability to participate in mass collaborations without even knowing those with whom we are collaborating. These new mass collaborations are implemented through 'wikis' and other publicly edited documents, and through interactive web 
sites that center on a particular theme, concern or topic. This class of mass collaboration has recently been explored brilliantly by Tapscott and Williams in their book entitled Wikinomics. Clearly this third class of collaboration is the most powerful, since it is strictly egalitarian by its very design. It has changed everything, and provided an opportunity for humans to adapt to an entirely new environment where the center is firmly on the question of 'what's right?', and not on the authoritative perspective of 'who's right?'. Now let's define specific concepts that will be important in the communication and evaluation of collaborations quite generally.

Trust,

Negotiations,

\section{Collaborations, and Scale}

Trust is essential in every human interaction, and hence it is manifested in different ways in every general class of collaboration as well. At a personal level, everyone who interacts with another will set their limits of interaction and hence their level of candor based on the level of trust that they have achieved with one another. At this level trust is based on the degree to which each individual is confident that the other will protect their well-being in the interaction. Hence this trust depends strongly on the assessment of each person of the motivations of the other, and on the value that each person perceives in the other to develop and nurture an ongoing relationship through the present interaction. When I interact with a person who I have just met, my level of candidness with this person will be based on what I think that the other person wants out of this interaction.
Does this reporter want a fair and balanced story, or is (s)he looking for cheap sensationalism to draw attention to themselves and their press organizations? Secondly, with that considered, do they see their interaction with me as a one-time 'hit and run' encounter, or as something that will build our trust in one another for many years to come? Such considerations are critical in deciding if I am ready to go 'off the record' to help this reporter who I just met to more completely understand the issues surrounding their topic of interest. In our personal interaction we 'test the waters' continuously by offering to be more candid and observing the response of the other. Trust over time is based not only on the other person's candor, but also on their demonstrated integrity to hold to their commitments, both stated and implied, to use the gained information in such a way that does not materially damage us as the source. While we all often interact with many other people than reporters, this example demonstrates effectively those aspects of our interaction that are used to define our level of interpersonal trust.

At the institutional level many of these same principles apply, but now trust is more based upon an aggregate understanding of the position and desires of each collaborating institution or organization. Trust becomes more objective, since it may be based upon an analysis of what each party stands to gain or lose in a given interaction, and on the record of each organization's past adherence to do as they agree to do. While personal trust and friendship between the negotiating parties in a 
business deal are critical to the willingness of each individual to sit down around the same table, once the business negotiation starts, it is (and by all rights should be) much more centered on defining how both institutional objectives may be further advanced through the proposed collaboration. In fact, the negotiation itself is simply the process by which the proposed collaboration is better refined to provide assurance of mutual value between the collaborating institutions. The process of negotiating such collaborations critically depends on the ability of the people who are negotiating to think selflessly and act at the higher composite level of the institution's representative, and not merely out of their personal concerns. Those who can do this most effectively are those who become the most valued to lead their respective organizations and institutions.

Negotiations that lead to collaborations between sovereign nations are quite similar to those described above between organizations and institutions, with one profound difference: There is no higher authority to police the process and hence to provide restitution in the case where either party proceeds unjustly or dishonestly. Hence the interactions between nations are profoundly influenced by the credible ability of either nation to wage war on the other, and negotiations between non-sovereign entities with sovereign entities are quite dangerous, as most Native Americans can attest. Niccoli Machiavelli recognized this difference clearly when he defined the powers of the sovereign in his book The Prince. The concept that the means justify the ends only holds at the position of the head of state, and never at lower levels. As the head of the State of Israel, what methods would you consider to be ethically off-limits in your efforts to avoid another attempted genocide of your people, as was attempted in the Holocaust? There are many examples throughout history of attempts to define a higher policing authority that nations are obligated to obey, either out of religious conviction, or out of fear of collective economic reprisal by the other nations of the world. Neither of these has proven effective, and neither will likely prevail in the future, in my opinion. The frustration over this fact was discussed eloquently by President Lincoln in his Second Inaugural Address in March, 1865, when he said of the two combatants within the Civil War: "Both read the same Bible, and pray to the same God; and each invokes His aid against the other." In sum, historically sovereign nations collectively respond only to power and the proposed outcome of their actions. This is a critical aspect to consider in any negotiation with, or between, sovereign powers. Attempts such as the League of National and the United Nations to impose global law on the basis of trade retaliation to hostile acts have generally failed, since these consequences for the obnoxious pursuit of a nation's self-interest is generally not of adequate consequence to limit outrageous national behavior.

So as time evolves, will there ever be a method of ensuring a positive global economy through the assurance of trust at the national scale, free of the 
treat of mass destruction and global war? Petty wars between superpowers have been effectively outlawed through concerns of escalation to nuclear mass destruction, and this has shifted the possibility of direct warfare between nations to only those nations that cannot retaliate against each other at this extreme level. Ironically, it is the desire for peace and security that has escalated the proliferation of nuclear weapons throughout the world. No one will directly threaten to destroy a nuclear power for fear of nuclear retaliation, yet every nuclear power understands their inability to use nuclear weapons in any aggressive pursuit to better their nation, and this fact alone has made nuclear weapons an absurd route to peace in the 'mutually assured destruction' sense. When the world's first nuclear submarine went underway, the basing of nuclear weapons became impossible to locate, and hence the ability of any country to win a nuclear war against another became clearly and absolutely impossible. Today we are under nuclear threat from groups with no assignable national identity, where no retaliation against a sovereign state is possible.

The future may offer another possibility to establish a peaceful world: As we transition to a true knowledgebased economy, the gainful efforts of the world's most creative people, connected together through the internet, has established a new global market for innovation and commerce, and this situation will likely strengthen indefinitely for the foreseeable time ahead. Image a situation where the United Nations had the power to drop a nation off of the world-wide web if that nation disrespected international law. Today, and more so in the future, such an action would devastate any single economy throughout the world. Such a policy could be enforced, since those nations at the perimeter of the offending state would have the power to physically interrupt land lines and fiber optics, and all but a few nations today could be blocked from satellite signal relay. Once such an action rises to the point that the economic impact would be truly devastating to the offending nation's economy, we will have a chance at securing an assured peace based upon ethical global rule. Once this situation presents we will have achieved a level of integrated global economy in which petty differentiations based upon our country of origin are insignificant compared to the collective value that all of us working together can achieve. At that point the world will be able to turn its full resources toward productive endeavors, and toward battling common threats, such as curing major human diseases. With the current emergence of exceptional power being gained through mass collaborations over the internet, it is not unrealistic to predict that such as day as this may come.

\section{Presentation at the Merrill Retreat}

I presented on two major collaborations that I have helped structure and lead over the last twelve years. The first was a fundamental physics collaboration between many universities in preparation for a fundamental physics mission in space, named "Critical Dynamics in Microgravity". This collaboration was sharp and narrow in its intellectual focus, using the capabilities and 
expertise at many locations (UNM, Caltech, Stanford, and other less directly involved institutions) to achieve the exceptionally difficult technical objective of understanding out-of-equilibrium.

The second major collaboration was quite different in its focus. It was called the New Mexico Consortium (of Universities), which operated the Institute for Advanced Studies within Los Alamos National Laboratory. This collaboration focused on four different primary research topics, and as such was quite broad intellectually. This collaboration created a close infrastructure for many different universities to work closely with Los Alamos National Laboratory.

Clearly future collaborations will be required between our major research institutions within the Midwest to build coherently on our strengths in the Animal Health Corridor. As this largescale collaboration moves more into human health, it will be important for us as a region to develop the infrastructure necessary to become a national powerhouse in translational medicine. Business ethics dictates that no one institution will be able to perform their own clinical trials that are necessary to bring their own medical products and drugs to market through FDA approval, so this alone will drive a much stronger regional collaboration between our institutions.

Our institutions have distinct strengths that are far more complementary than they are competitive. As such, possibly we could define a regional task force between all regional institutions that want to participate to define genuinely new ways to address major problems. Teams between peer institutions will naturally self-assemble to take on major challenges that we could not address otherwise. Great advantages will be realized by those regions of the United States that learn how to collaborate gainfully over a vast range of scales. We look forward to being a critical part of this essential process. 